\title{
Continent Catheterizable Diversion
}

National Cancer Institute

\section{Source}

National Cancer Institute. Continent Catheterizable Diversion. NCI Thesaurus. Code C127176.

Continent urinary diversion procedure in which the surgically-created pouch requires a catheter to be inserted to drain the urine. 